\title{
A Review of Common Independent Variables Used in Tobacco Smoking Related Studies
}

\author{
Kaiye Gao ${ }^{1}$, Li Qu ${ }^{1 *}$, Huiying Wang ${ }^{2}$, Wentao Liu ${ }^{1}$, Bin Cheng ${ }^{1}$, Zhunan $\mathrm{Wu}^{1}$, Ying Liu ${ }^{1}$ and Rui \\ Peng $^{3}$ \\ ${ }^{1}$ School of Economics and Management, Beijing Information Science and Technology University, China \\ ${ }^{2}$ School of Economics and Management, University of Science and Technology Beijing, China \\ ${ }^{3}$ School of Economics and Management, Beijing University of Technology, China \\ *Corresponding author: $\mathrm{Li} \mathrm{Qu}$, School of Economics and Management, Beijing Information Science and Technology University, \\ China
}

\section{ARTICLE INFO}

Received: 幽 February 20, 2020

Published: 幽 February 28, 2020

Citation: Kaiye G, Li Q, Huiying W, Wentao L, Bin C, etc., A Review of Common Independent Variables Used in Tobacco Smoking Related Studies. Biomed J Sci \& Tech Res 26(1)-2020. BJSTR. MS.ID.004302.

\section{ABSTRACT}

Aim: To provide a reference for the independent variables selection in tobacco smoking related studies.

Background: Tobacco smoking has long been one of the leading causes of preventable death worldwide. Plenty of smoking-related studies including many reviews have been conducted. However, there is still no literature that reviews the independent variables of smoking.

Objective: Review the tobacco smoking related studies according to the independent variables used.

Method: We searched the academic literatures for this review according to the different independent variables which are binary variables of smoking status, multivariate variables of smoking status, smoking amount and others including duration of smoking cessation, age at starting smoking and tobacco types.

Result: Independent variables educed from smoking status are most widely used in previous studies since the smoking status, such as smoking or not and smoking cessation or not, is easy to be collected accurately. Smoking amount is usually used to distinguish the level of smoking, that is, how heavy are smokers' smoking behaviors.

Conclusion: According to our review, we found that it is needed to construct some new forms for the independent variables of smoking to analyze the effect of smoking on the advance.

Keywords: Tobacco Smoking; Independent Variable; Smoking Status; Smoking Amount; Smoking Cessation; Tobacco Types

\section{Introduction}

Tobacco is the only legal drug, killing many of tobacco users when used exactly as intended by its manufacturers. According to the report of World Health Organization, tobacco use including smoking and smokeless is currently responsible for about six million deaths across the world each year [1]. This figure includes about 600,000 people who may die from the effects of secondhand smoke. Tobacco smoking has been proved associated with ill health, disability and death from non-communicable chronic diseases. However, it also leads to an increased risk of death from communicable diseases. Thus, tobacco use is still one of the biggest preventable causes of diseases and premature deaths until now. Although smoking rates fell in the higher income countries during the 1970s and 1980s, evidence shows that this trend is levelling out [2]. The importance of revealing studying and evaluating the effects of smoking on health is obvious. Herein, the effects of tobacco smoking on specific diseases such as chronic obstructive 
pulmonary disorders, cardiovascular diseases, respiratory diseases, as well as cancers of lung, oral cavity, larynx, oesophagus, stomach, pancreas, colorectum, bladder and kidney etc. have been found for many years [3].

However, researchers conducted studies using different independent variables for different areas. Most studies used a binary variable to indicate the smoking or smoking cessation [416]. Some researchers further classified the variable into three groups including never smokers, ex-smokers and current smokers [17-23]. Furthermore, some researchers used the conception of smoking amount like the cigarettes smoked per day to classify the study population into some subgroups when they study the effects of smoking [24-32]. Moreover, there also some other forms of independent variables have been used such as duration of smoking cessation [33-38], age at starting smoking [39-41] and tobacco types $[14,15,31,42]$. Although there already have been plenty of tobacco smoking related reviews, the independent variables used in the studies of tobacco smoking still have not been systematic reviewed. With the development of the technology and the theory, health care can be implemented in many different ways, such as the semantic Web of Things [43] which promotes the secure semantic smart health care [44] and the facial expression recognition [45] which promotes the smart psychological health management. As a results, the health information has been increasingly complicated and then it is important to choose the reasonable variables for analyses.

Herein, this study will review the independent variables used in previous smoking studies. The regular questions to collect the relating independent variables will be summarized. The appropriate regression models as well as their advantages and disadvantages will be listed. This study may help the researchers of tobacco smoking to choose the appropriate independent variables

Table 1: The questions about smoking in CHNS questionnaire. for their studies. The remaining of this paper is arranged as follows. Section 2, Section 3, Section 4 and Section 5 summarize the studies relating binary variables of smoking, multivariate variables of smoking, smoking amount, and others including duration of smoking cessation, age of starting smoking and tobacco types. Section 6 concludes this study. Section 7 points out some future works.

\section{Questions of Data Collection}

In this section, we provide two examples of questionnaire to show the regular questions about smoking, which can be used to collect the data for the independent variables of smoking for analysis. The first example is from the questionnaire of Chinese Health and Nutrition Survey (CHNS), which is a longitudinal survey organized by the Carolina Population Centre at the University of North Carolina at Chapel Hill, USA, and the National Institute of Nutrition and Food Safety at the Chinese Centre for Disease Control and Prevention. Table 1 shows the part of smoking in the questionnaire of CHNS. As shown in Table 1, the researchers can obtain the smoking status including never smoker, current smokers, ex-smokers (questions 1 and 3), smoking amount (cigarettes smoked per day) (question 4), the age of starting smoking (question 2), as well as the duration of smoking cessation (question 5). However, CHNS questionnaire did not provide the definition of smoking. Then, we present another questionnaire of a longitudinal survey which focuses on smoking. This survey is organized by Chinese Center for Disease Control and Prevention. The section of smoking in questionnaire of this survey are shown in Table 2. As shown in Table 2, this questionnaire is more detailed. In addition to smoking status (questions 1 and 2), smoking amount (question 5), age of starting smoking (question 3) and duration of smoking cessation (question 8), we can also have the tobacco types smoked (question 5) and the reason for smoking cessation (question 7).

\begin{tabular}{|c|c|c|}
\hline Number & Question & Answers \\
\hline 1 & $\begin{array}{l}\text { Have you ever smoked cigarettes (including hand-rolled or } \\
\text { device -rolled) }\end{array}$ & $\begin{array}{l}\text { 0. never smoked (skip to the next section) } \\
\text { 1. yes } \\
\text { 2. unknown (skip to the next section) }\end{array}$ \\
\hline 2 & How old were you when you started to smoked? (years) & - \\
\hline 3 & Do you still smoke cigarettes now? & $\begin{array}{l}\text { 0. never smoked (skip to Question 5) } \\
\text { 1. yes } \\
\text { 2. unknown (skip to Question 5) }\end{array}$ \\
\hline 4 & How many cigarettes do you smoked per day? & (Skip to the next section) \\
\hline 5 & How long ago did you stop smoking? (months) & If unknown, just record -99 \\
\hline
\end{tabular}

Table 2: The questions about smoking in a Chinese longitudinal smoking survey*.

\begin{tabular}{|c|c|c|}
\hline Number & Question & Answers \\
\hline 1 & Do you smoke now? & $\begin{array}{c}\text { 1. no yes } \\
\text { If yes, go to Question 3 }\end{array}$ \\
\hline 2 & Did you ever smoked before & 0. no \\
& & 1. yes \\
If no, go to next section
\end{tabular}




\begin{tabular}{|c|c|c|}
\hline 3 & At about what age did you first start smoking? & - \\
\hline 4 & Have you ever habitually smoked factory cigarettes? & $\begin{array}{l}0 . \text { no } \\
\text { 1. yes }\end{array}$ \\
\hline $4(1)$ & If so: at about what age did you start? & - \\
\hline 5 & About how much tobacco did you usually smoke? & $\begin{array}{l}\text { 1. Pipe or water pipe (Liang/month) } \\
\text { 2. Hand-rolled cigarettes (Liang/month) } \\
\text { 3. Cigars (Number/day) } \\
\text { 4. Non-filter cigarettes (Number/day) } \\
\text { 5. Filter cigarettes (Number/day) }\end{array}$ \\
\hline 6 & Have you ever stopped smoking before & $\begin{array}{l}0 . \text { No } \\
1 \text {. Yes }\end{array}$ \\
\hline $6(1)$ & If so: when was it? & $\begin{array}{l}\text { 1. Less than half-year ago } \\
\text { 2. Not less than half-year ago }\end{array}$ \\
\hline 7 & What was your main reason for stopping? & $\begin{array}{l}\text { 1. Illness } \\
\text { 2. Money } \\
\text { 3. Family pressure } \\
\text { 4. Health education } \\
\text { 5. Other }\end{array}$ \\
\hline 8 & How many years have you stopped smoking & - \\
\hline
\end{tabular}

Note: *Definition of smoking: smoking on most days for at least half a year

\section{Binary Variables of Smoking Status}

This section provides a review of studies using the binary variable of smoking status. The binary variable of smoking status usually classifies the study sample in three cases, that is, smokers and never smokers/non-smokers, current smokers and never smokers/non-smokers, or smokers and ex-smokers. Binary variables of smoking status are easy to be obtained. They are the basic information of smoking in a survey questionnaire. Thus, they are most widely used in the smoking-related studies and most of them are basic qualitative analysis, as below.

\section{Smokers versus Never Smokers/Non-Smokers}

By separating the volunteers into smokers and never smokers/ non-smokers, many researchers studied the relationship between smoking and specific diseases. Amaral et al. improved the method of early diagnosis of smoking-induced respiratory changes using machine learning algorithms [4]. Feldman and Anderson revealed the relationship between the cigarette smoking and mechanisms of susceptibility to infections of the respiratory tract and other organ systems [5]. Ayyagari and Kessler studied the association between smoking and cognitive functioning at older ages according to the evidence from the health and retirement study [6]. Brody et al. studied the effect of cigarette smoking on a marker for neuroinflammation with a [11C] DAA1106 positron emission tomography study [7].

\section{Current Smokers Versus Never smokers/Non-Smokers}

Some researches separated the study population into current smokers and never smokers/non-smokers. Yoshida et al. discussed the effects of tiotropium on lung function among current smokers and never smokers with bronchial asthma [8]. Torén et al. founded reference values of fractional excretion of exhaled nitric oxide among non-smokers and current smokers [9].

\section{Current Smokers Versus Ex-Smokers (former Smokers)}

Some researchers studied the effects of smoking cessation by grouping the smokers into current smokers and ex-smokers (former smokers). Au et al. studied the effects of smoking cessation on the risk of chronic obstructive pulmonary disease exacerbations [10]. O'Hara et al. provided the evidence for the early and late weight gain following smoking cessation in the lung health study [11]. Campling et al. studied the disparity in age at lung cancer diagnosis between current and former smokers [12]. Mccarthy et al. found the social disparities in unaided quit attempts among daily current and former smokers based on the results from the 2010-2011 tobacco use supplement to the current population survey [13]. Jensen et al. studied the effect of nicotine, silver acetate, and placebo chewing gum on the cessation of smoking and the influence of smoking type and nicotine dependence [14]. Pollak and Mullen presented a study for an exploration of the effects of partner smoking, type of social support, and stress on postpartum smoking in married women who stopped smoking during pregnancy [15]. Higgins et al. studied the effects of cigarette smoking cessation on breastfeeding duration [16].

\section{Multivariate Variables of Smoking Status}

This section provides studies review of the multivariate variables of smoking status. The multivariate variables of smoking status usually classify the study samples in three groups which are never smokers/non-smokers, current smokers and ex-smokers/ former smokers. The multivariate variables of smoking status are also easy to collected. In this case, we can further classify the population into more than two groups according to the smoking status. Most of the relating studies are qualitative analysis, as below. Many researchers conducted studies for current smokers, never smokers/non-smokers and ex-smokers/former smokers. Jones et al. studied the disease severity for different populations of 
smoking with axial spondyloarthritis according to the results from the Scotland registry for ankylosing spondylitis [17]. Morabia and Wynder discussed the dietary habits of smokers, people who never smoked, and ex-smokers [18]. Yi et al. revealed the probability of developing coronary atherosclerosis among ex-smokers and never smokers from the coronary CT angiography findings based on smoking status [19]. Frank et al. studied the relationship between smoking, respiratory symptoms and likely asthma in young people based on the evidence from postal questionnaire surveys in the Wythenshawe Community Asthma Project [20]. Crispo et al. studied the cumulative risk of lung cancer among current, ex- and never-smokers in European men [21]. Hobbs et al. found that the low incidence of surgery for non-cardiac vascular disease in UK Asians may be explained by a low prevalence of disease [22]. Tanni et al. studied the association between smoking status and tumor necrosis factor-alpha mediated systemic inflammation in COPD patients [23].

\section{Smoking Amount}

This section provides studies review of the smoking amount. Smoking amount measures the level of smoking, so it can be used in two ways in the smoking-related studies. The first way is to directly use the smoking amount as a continuous independent variable. The other way is to use the smoking amount to classify the smokers into several groups such as light smokers, moderate smokers and heavy smokers. Smoking amount usually are not easy to be recorded accurately since it is an ambiguous, inconstant variable. In this case, it is recommended to use smoking amount jointly with other independent variables like smoking status. For example, the never smokers can be seen as a reference group when the smokers are classified into light smokers and heavy smokers according to smoking amount to study the effect of smoking on the risks of some specific diseases.

Buechley et al. studied the relationship of amount of cigarette smoking to coronary heart disease mortality rates in men [24]. Robinson et al. conducted a comparative study of the amount of smoke absorbed from low yield cigarettes with both non-invasive and invasive measures $[25,26]$. Weijenberg et al. discussed the cigarette smoking and KRAS oncogene mutations in sporadic colorectal cancer based on the results from the Netherlands Cohort Study [27]. Mulder et al. studied the effect of smoking and time since quitting on the smoking cessation and quality of life [28]. Glasgow et al. studied the self-help books and amount of therapist contact in smoking cessation programs [29]. Jonh et al. studied the relationship between nicotine dependence and lifetime amount of smoking in a population sample [30]. Hammond revealed the inhalation in relation to type and amount of smoking [31]. Gao et al. proposed a new form of independent variable educed from the number of cigarettes smoked per day [32]

\section{Other Variables}

Except smoking status and smoking amount, there are also some other independent variables that can be used in the tobacco smoking related studies such as the duration of smoking cessation, age of starting smoking, as well as tobacco types. This section provides gives the studies review for these variables.

\section{Duration of Smoking Cessation}

The duration of smoking cessation is the time span from the smoking cessation. It is usually used to study the effects of smoking cessation. Au et al. using the duration of smoking cessation studied the effect of smoking cessation on the risk of chronic obstructive pulmonary disease exacerbations [10]. Lapperre studied the relation between duration of smoking cessation and bronchial inflammation in COPD [33]. Nishihara et al. presented a prospective study of duration of smoking cessation and colorectal cancer risk by epigenetics-related tumor classification [34]. Lee et al. discussed the cumulative smoking exposure, duration of smoking cessation, and peripheral arterial disease in middle-aged and older Korean men [35]. Kweon et al. studied the effects of cumulative smoking exposure and duration of smoking cessation on carotid artery structure [36]. Yun et al. revealed the association of smoking status, cumulative smoking, duration of smoking cessation, age of starting smoking and depression in Korean adults [37]. Hazlinda et al. studied the impact of the duration of smoking cessation on hospital admission and health-related quality of life amongst COPD patients [38].

\section{Age of Starting Smoking}

The age of starting smoking is usually used to study the longterm impact of smoking on health. Yun et al. studied the association of smoking status, cumulative smoking, duration of smoking cessation, age of starting smoking, age of starting smoking and depression in Korean adults [37]. Sax studied the relationship between age of starting smoking and number of cigarettes smoked in Catalonia, Spain [39]. Zhu et al. presented an analysis of the relationship between cigarette smoking and nasopharyngeal cancer according to age of starting smoking and age of diagnosis [40]. Schneider et al. found the trends and correlates for the average age of smoking onset in Germany [41].

\section{Tobacco Types}

The tobacco types are important for smokers since different tobacco types may have different degree of addiction and different influences on health. Natto et al. studied the effects of smoking on periodontal health for different smokers including water pipe smokers, cigarette smokers and mixed smokers. Hammond studied the inhalation in relation to type and amount of smoking [31]. Jensen et al. studied the effect of nicotine, silver acetate, and 
placebo chewing gum on the cessation of smoking and the influence of smoking type and nicotine dependence [14]. Pollak and Mullen presented a study for an exploration of the effects of partner smoking, type of social support, and stress on postpartum smoking in married women who stopped smoking during pregnancy [15] Baldassarre et al. studied the effects of timing and extent of smoking, type of cigarettes, and concomitant risk factors on the association between smoking and subclinical atherosclerosis [42].

\section{Conclusion}

This paper presents a review of independent variables of smoking used in smoking-related studies. We classify the independent variables into binary variables of smoking, multivariate variables of smoking, smoking amount and others including duration of smoking cessation, age of starting smoking and tobacco types. Independent variables educed from smoking status are most widely used in previous studies since the smoking status, such as smoking or not and smoking cessation or not, is easy to be collected accurately. Smoking amount is usually used to distinguish the level of smoking, that is, how heavy are smokers' smoking behaviors.

\section{Current \& Future Developments}

Although a lot of smoking-related studies have been carried out, more new forms of independent variables of smoking are needed to conduct smoking-related studies as research of smoking go on. In the future, the independent variable of smoking may be developed for two kinds of research: 1). the research about e-cigarettes; and 2). the research of the quantitative effects of smoking.

\section{Conflict of Interest}

There is no conflict of interest for this study.

\section{Acknowledgement}

This study is partially founded by National Natural Science Foundation of China under grant number 71671016 and the Research Base Project of Social Science Foundation of Beijing under grant number 19JDGLB019.

\section{References}

1. (2015) Word Health Organization, WHO global report on trends in prevalence of tobacco smoking. WHO Press: Geneva?

2. Samet JM, Yoon SY (2001) Woman and the tobacco epidemic: Challenges for the $21^{\text {st }}$ century, Geneva: World Health Organization.

3. Doll R, Peto R, Wheatley K, Gray R, Sutherland I (1994) Mortality in relation to smoking: 40 years' observations on male British doctors. BMJ 309(6959): 901-911

4. Amaral JL, Lopes AJ, Jansen JM, Faria AC, Melo PL (2013) An improved method of early diagnosis of smoking-induced respiratory changes using machine learning algorithms. Comput Meth Prog Bio 112(3): 441-454.

5. Feldman C, Anderson R (2013) Cigarette smoking and mechanisms of susceptibility to infections of the respiratory tract and other organ systems. J Infect 67(3): 169-184.
6. Ayyagari P, Kessler AS (2015) Smoking and cognitive functioning at older ages: Evidence from the health and retirement study. J Econ Ageing 6: 13-23.

7. Brody AL, Hubert R, Enoki R, Garcia LY, Mamoun MS, et al. (2017) Effect of Cigarette Smoking on a Marker for Neuroinflammation: A [11C] DAA1106 Positron Emission Tomography Study Neuropsychopharmacol. 42: 1630-1639.

8. Yoshida M, Kaneko Y, Ishimatsu A, Komori M, Iwanaga T, et al. (2017) Effects of tiotropium on lung function in current smokers and never smokers with bronchial asthma. Pulm Pharmacol Ther 42(suppl 59): 7-12.

9. Torén K, Murgia N, Schiöler L, Bake B, Olin AC (2017) Reference values of fractional excretion of exhaled nitric oxide among non-smokers and current smokers. BMC Pulm Med 17(1): 118-124.

10. Au DH, Bryson CL, Chien JW, Sun H, Udris EM, et al. (2009) The effects of smoking cessation on the risk of chronic obstructive pulmonary disease exacerbations. J Gen Inter Med 24(4): 457-463.

11. O’Hara P, Connett JE, Lee WW, Nides M, Murray R, et al. (1998) Early and late weight gain following smoking cessation in the lung health study. Am J Epidemiol 148(9): 821-830.

12. Campling BG, Ye Z, Lai Y, Li L, Bar-Ad V, et al. (2019) Reference values of fractional excretion of exhaled nitric oxide among non-smokers and current smokers. J Cancer Res Clin 145: 1243-1251.

13. McCarthy M, Siahpush M, Shaikh RA, Sikora Kessler A, Tibbits M (2017) Social disparities in unaided quit attempts among daily current and former smokers: Results from the 2010-2011 tobacco use supplement to the current population survey. Nicotine Tob Res 18(8): 1705-1710.

14. Jensen EJ, Schmidt E, Pedersen B, Dahl R (1991) The effect of nicotine, silver acetate, and placebo chewing gum on the cessation of smoking. the influence of smoking type and nicotine dependence. Int J Addict 26(11): 1223-1231.

15. Pollak KI, Mullen PD (1997) An exploration of the effects of partner smoking, type of social support, and stress on postpartum smoking in married women who stopped smoking during pregnancy. Psychol Addict Behavi 11(3): 182-189.

16. Higgins TM, Higgins ST, Heil SH, Badger GJ, Skelly JM, et al. (2010) Effects of cigarette smoking cessation on breastfeeding duration. Nicotine Tob Res 12(5): 483-488.

17. Jones GT, Ratz T, Dean LE, Macfarlane GJ, Atzeni F (2017) Disease severity in never smokers, ex-smokers, and current smokers with axial spondyloarthritis: Results from the scotland registry for ankylosing spondylitis. Arthrit Care Res 69(9): 1407-1413.

18. Morabia A, Wynder EL (1990) Dietary habits of smokers, people who never smoked and exsmokers. Ame J Clin Nutr 52(5): 933-937.

19. Yi M, Chun EJ, Lee MS, Lee J, Choi SI (2015) Coronary CT angiography findings based on smoking status: Do ex-smokers and never-smokers share a low probability of developing coronary atherosclerosis? Interna J Cardiovascul Ima 31: 169-176.

20. Frank P, Morris J, Hazell M, Linehan M, Frank T (2006) Smoking, respiratory symptoms and likely asthma in young people: Evidence from postal questionnaire surveys in the Wythenshawe Community Asthma Project (WYCAP). BMC Pulmonary Med 6: 10.

21. Crispo A, Brennan P, Jöckel KH, Schaffrath-Rosario A, Wichmann HE, et al. (2004) The cumulative risk of lung cancer among current, ex- and never-smokers in European men. Br J Cancer 91(7): 1280-1286.

22. Hobbs SD, Sam RC, Bhatti A, Rehman A, Wilmink AB (2006) The low incidence of surgery for non-cardiac vascular disease in UK Asians may be explained by a low prevalence of disease. Eur J Vasc Endovasc 32(5): 494-499. 
23. Tanni SE, Pelegrino NR, Angeleli AY, Correa C, Godoy I (2010) Smoking status and tumor necrosis factor-alpha mediated systemic inflammation in COPD patients. J Inflamm 7: 29.

24. Buechley RW, Drake RM, Breslow L (1958) Relationship of amount of cigarette smoking to coronary heart disease mortality rates in men. Circulat 18(6): 1085-1090

25. Robinson JC, Young JC, Rickert WS (1982) A comparative study of the amount of smoke absorbed from low yield ('less hazardous') cigarettes. part 1: Non-invasive measures. Br J Addict 77(4): 383-397.

26. Robinson JC, Young JC, Rickert WS, Fey G, Kozlowski LT (1983) A comparative study of the amount of smoke absorbed from low yield ('less hazardous') cigarettes part 2: Invasive measures. Br J Addict 78(1): 79-87.

27. Weijenberg MP, Aardening PW M, de Kok TM, de Goeij AF PM, van den Brandt PA (2006) Is smoking a risk factor for decreased semen quality? a cross-sectional analysis. Hum Reprod 22: 188-196.

28. Mulder I, Tijhuis M, Smit HA, Kromhout D (2001) Smoking cessation and quality of life: The effect of amount of smoking and time since quitting. Prev Med 33(6): 653-660.

29. Glasgow RE, Schafer L, O’Neill HK (1981) Self-help books and amount of therapist contact in smoking cessation programs. J Consult Clin Psychol 49(5): 659-667.

30. John U, Meyer C, Hapke U, Rumpf HJ (2004) Nicotine dependence and lifetime amount of smoking in a population sample. Eur J Public Health 14(2): 182-185.

31. Hammond EC (1959) Inhalation in relation to type and amount of smoking. J Am Stat Assoc 54(285): 35-51.

32. Gao K, Shi X, Wang W (2001) The life-course impact of smoking on hypertension, myocardial infarction and respiratory diseases. Sci Rep 7: $1-7$.

33. Lapperre TS, Postma DS, Gosman MM E, Snoeck-Stroband, Ten Hacken NH T (2006) Relation between duration of smoking cessation and bronchial inflammation in COPD. Thorax 61(2): 115-121.

34. Nishihara R, Morikawa T, Kuchiba A, Lochhead P, Yamauchi M, et al. (2013) A prospective study of duration of smoking cessation and colorectal cancer risk by epigenetics-related tumor classification. Am J of Epidemiol 178(1): 84-100.

\section{ISSN: 2574-1241}

DOI: 10.26717/BJSTR.2020.26.004302

Li Qu. Biomed J Sci \& Tech Res

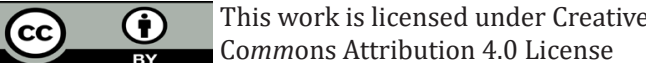

Submission Link: https://biomedres.us/submit-manuscript.php
35. Lee YH, Shin MH, Kweon SS, Choi JS, Park KS (2011) Cumulative smoking exposure, duration of smoking cessation, and peripheral arterial disease in middle-aged and older Korean men. BMC Public Health 11: 94.

36. Kweon SS, Lee YH, Shin MH, Choi JS, Rhee JA, et al. (2012) Effects of cumulative smoking exposure and duration of smoking cessation on carotid artery structure. Circ J 76(8): 2041-2047.

37. Yun WJ, Shin MH, Kweon SS, Ryu SY, Rhee JA (2012) Association of smoking status, cumulative smoking, duration of smoking cessation, age of starting smoking, and depression in korean adults. BMC public health 12: 724-730.

38. Hazlinda AH, Noorizan AA, Yahaya H, Fahmi H (2014) Does the duration of smoking cessation have an impact on hospital admission and healthrelated quality of life amongst COPD patients? Int J Chron Obstruct Pulmon Dis 14: 493-499.

39. Sax A (1999) Age at starting smoking and number of cigarettes smoked in Catalonia, Spain. Rrev Med 28: 361-366.

40. Zhu K, Levine RS, Brann EA, Gnepp DR, Baum MK (1997) Cigarette smoking and nasopharyngeal cancer: An analysis of the relationship according to age at starting smoking and age at diagnosis. J Epidemiol $7(2): 107-111$.

41. Schneider S, Mohnen SM, Pust S (2008) The average age of smoking onset in Germany-trends and correlates. Int J Public Health 53: 160-164.

42. Baldassarre D, Castelnuovo S, Frigerio B, Amato M, Werba JP (2009) Effects of timing and extent of smoking, type of cigarettes, and concomitant risk factors on the association between smoking and subclinical atherosclerosis. Stroke 40(6): 1991-1998.

43. Mishra S, Jain S, Rai C, Gandhi N (2018) Security Challenges in Semantic Web of Things. International Conference on Innovations in Bio-Inspired Computing and Applications pp. 162-169.

44. Tiwari SM, Jain S, Abraham A, Shandilya S (2018) Secure Semantic Smart HealthCare (S3HC). J Web Eng 17(8): 617-646.

45. Rahul M, Kohli N, Agarwal R, Mishra S (2019) Facial expression recognition using geometric features and modified hidden Markov model. Int J of Grid Utility Comput 10: 488-496.

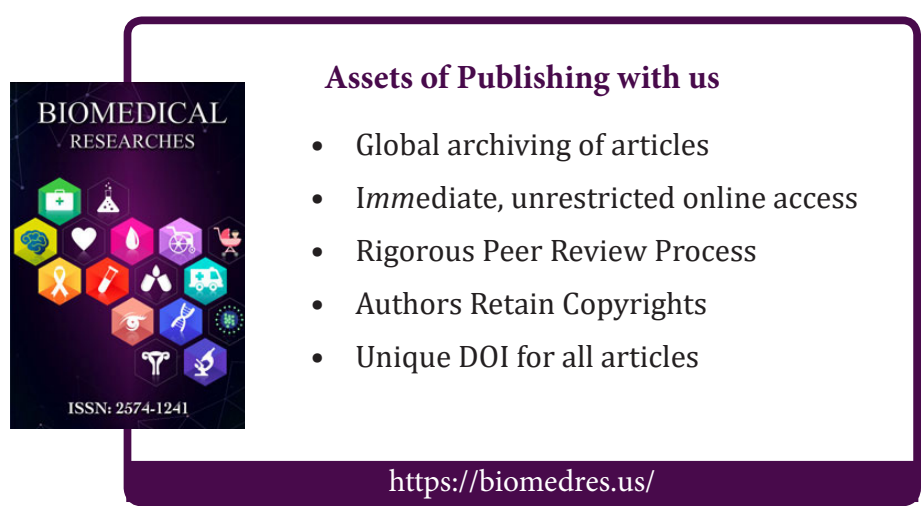

